\title{
Physicochemical properties of yttria-stabilized-zirconia in-flight particles during supersonic atmospheric plasma spray
}

Guozheng Ma ${ }^{\mathrm{a}}$, Shuying Chen ${ }^{\mathrm{b}, *}$, Kang Jiajie ${ }^{\mathrm{c}, *}$, Haidou Wang ${ }^{\mathrm{a}}$, Ming Liu ${ }^{\mathrm{a}}$, Qin

$$
\text { Zhao }^{\mathrm{a}, \mathrm{d}}, \text { GuoLu Li }{ }^{\mathrm{d}} \text {, Pengfei } \mathrm{He}^{\mathrm{a}}
$$

(a National Key Lab for Remanufacturing, Army Academy of Armored Forces, Beijing 100072, China;

b National Key Laboratory of Human Factors Engineering, China Astronaut Research and Training Center, Beijing 100094, China;

c School of Engineering and Technology, China University of Geosciences, Beijing 100083, China;

d School of Materials Science and Engineering, Hebei University of Technology,

$$
\text { Tianjin 300130, China.) }
$$

*Corresponding author. Tel.: +8610 66718475; fax: +861066717144.

E-mail address: chenshuying90@163.com (S. Y. Chen); kangjiajie@cugb.edu.cn (J. J.

$$
\text { Kang) }
$$

\footnotetext{
Abstract: In order to achieve better knowledge of the thermal barrier coatings (TBCs) by supersonic atmospheric plasma spraying (SAPS) process, an experimental study was carried out to elaborate physicochemical properties of particles in-flight during the SAPS process. One type of commercially available agglomerated and sintered yttria-stabilized-zirconia (YSZ) powders were injected into the SAPS plasma jet and collected by shock chilling method. The YSZ particles in-flight physicochemical properties of the melting state, morphology, microstructure, particle size distribution,
} 
element composition changes and phase transformation during the SAPS process have been systematically analyzed. The melting state, morphology and microstructure of the collected particles were determined by scanning electron microscopy (SEM). The particle size distribution was measured by a laser particle size analyzer (LPSA). Element compositions were quantitatively analysed by an electron probe X-ray microanalyzer (EPMA). Additionally, the X-ray diffraction (XRD) method was used to analyse the phase transformation. The results showed that the original YSZ powders injected into the SAPS plasma jet were quickly heated and melted from the outer layer companied with breakup and collision-coalescence. The outer layer of the collected particles containing roughly hexagonal shaped grains exhibited a surface texture with high sphericity and the inside was dense with hollow structure. The median particle size was decreased from $45.65 \mu \mathrm{m}$ to $42.04 \mu \mathrm{m}$. Besides, phase transformation took place and the content of zirconium $(\mathrm{Zr})$ and yttrium $(\mathrm{Y})$ element was decreased with the evaporation of $\mathrm{ZrO}_{2}$ and $\mathrm{Y}_{2} \mathrm{O}_{3}$.

Keywords: plasma spray; in-flight particles; molten status; YSZ

\section{Introduction}

Thermal barrier coatings (TBCs), which can provide thermal insulation to the engine hot components and protect them from corrosion and oxidation at high temperature as well, play an important role in advanced gas-turbine and diesel engines [1-3]. A typical TBCs system consists of two layers over the super alloy substrate: a metallic bond-coat and a ceramic top-coat, where yttria-stabilized-zirconia $\left(\mathrm{Y}_{2} \mathrm{O}_{3}\right.$ stabilized $\mathrm{ZrO}_{2}$, YSZ) is a widely used material as the top coat owing to its low 
thermal conductivity, high thermal expansion coefficient and good mechanical properties [4-5]. To date, electron beam physical vapor deposition (EB-PVD) and atmospheric plasma spraying (APS) are two main processes to prepare YSZ coatings. In particular, APS is a commercial, high-efficiency process and easy to operate, in which original powders are injected into plasma jet with carrier gas and quickly heated and accelerated. Successive particles in-flight impinge onto substrate followed by spreading and rapid solidification to form single splats. The as-sprayed coating develops with the stacking of these flattened splats [6-7].

At present, empirically tuning 3-6 main controllable parameters is the main method to find the relationship between the spray parameters and the coating [8-9]. However, APS is a complicated process in which more than 35 main parameters both controllable parameters (such as the flow rate of gas, power, etc.) and some uncontrollable parameters like the erosion of the electrode and fluctuations in the particles injection geometry are identified to influence the resulting microstructure and correspondingly coating properties [10]. Therefore, it's a great challenge to produce reproducible and reliable plasma sprayed coatings. In the recent years, particles in-flight properties have been studied theoretically, numerically and experimentally and suggested no matter how complicated the influence parameter is, physicochemical properties of particles in-flight before impinging onto substrate are fundamental parameters influencing the quality of the as-sprayed coatings [11-16]. Liu et al. [11] used Box-Behnken Design experimental method to analyze the effect of spray parameters on average velocity and surface temperature of $\mathrm{La}_{2} \mathrm{Ce}_{2} \mathrm{O}_{7}$ particles 
in-flight and its influence on the microstructure and mechanical properties. Bai et al. [12] adopted one-factor-at-a-time method to investigated the effect of four spray parameters on average velocity and temperature of nanostructured YSZ particles in-flight and theoretically quantify the influence of in-flight particles melting state on the microstructure of as-sprayed coatings. Choudhury et al. [13-14] utilized Artificial Neural Network (ANN) to quantify the relationship between processing parameters and $\mathrm{Al}_{2} \mathrm{O}_{3}-\mathrm{TiO}_{2}$ particles in-flight characteristics and to establish process controls by predicting the particle in-flight characteristics of the APS process. Wei et al. [15] analyzed the melting state and refining behavior of particles flight during spraying using numerical method. Tekmen et al. [16] investigated oxidation behavior of $\mathrm{Al}$ particles in-flight and the effects of velocity and temperature particles in-flight on the oxidation mechanism.

Lately, an advanced high efficiency and low energy consumption (lower than 80 $\mathrm{kW}$ ) supersonic atmospheric plasma spraying (SAPS) process has been successfully developed by Academy of Armored Forces Engineering (Beijing, China) [17-18]. The main components of this novel system are plasma gun, powder feeder, gas-supply system, cooling water system and power supply system and control system. Fig. 1 shows the schematic diagram of the supersonic plasma spraying system. The key of this system is a novel SAPS gun with a Laval nozzle and internal feedstock injection mode which makes the feedstock particles can be heated and accelerated adequately and has no limitation to the melting temperature of the sprayed materials and has more advantage in fabricating high performance ceramic, cermet or metallic coatings 
than APS. However, physicochemical properties of YSZ particles in-flight during the SAPS process have not yet been systematically studied.

Motivated by the aforementioned considerations, this study is dedicated to understand the physicochemical properties of YSZ particles in-flight by experimental methods to achieve better knowledge of TBCs by the SAPS process. Whereas, it is difficult to directly observe the physicochemical properties of YSZ particles in-flight during the SAPS process for its high temperature and velocity. In this paper, a shock chilling method was employed to trap the YSZ particles in-flight after passing a usual spraying distance during the SAPS process. The YSZ particles in-flight physicochemical properties of the melting state, morphology, microstructure, particle size distribution, element composition changes and phase transformation were investigated in detail during the SAPS process.

\section{Experimental material and methods}

Experiments were carried out on a SAPS system (HEPJ-II, China) and the plasma gun was mounted on a 6-axis robot (MOTOMAN-2010, Ysakawa, Japan). Details of the spraying parameters are listed in Table 1, in which argon and hydrogen were used as the primary and assistant gas, respectively. One type of commercially available agglomerated and sintered (AS) 6-8 wt. \% $\mathrm{Y}_{2} \mathrm{O}_{3}-\mathrm{ZrO}_{2}$ (YSZ) particles was used as feedstock. To collect particles in-flight before impinging onto substrate, an experimental apparatus was developed (as illustrated in Fig. 2). During the SAPS process, YSZ particles in-flight were rapidly solidified and collected in a collection apparatus containing liquid nitrogen in which the cooling rate of the spraying particles 
exceeds $10^{6} \mathrm{~K} / \mathrm{s}$ that enables a rapid cooling rate [19]. Furthermore, liquid nitrogen, an inert cooling medium, was used to prevent chemical reaction from occurring between the YSZ particles in-flight and the cooling medium. Thus, this shock chilling method could be used to characterize the physicochemical properties of YSZ particles in-flight. The collection apparatus was positioned vertically to the SAPS gun to enable the YSZ particles in-flight flying into liquid nitrogen. The trapped particles were extracted from the resulting suspension by a membrane filter with pore diameter of $0.1 \mu \mathrm{m}$ and then dried in a vacuum drying box. The external and internal morphology of the original AS YSZ powders (referred as O-AS) and collected YSZ particles (referred as C-AS) were determined by a scanning electron microscope (SEM, ZEISS, Germany). The particle size distribution of the O-AS powders and C-AS particles was measured by a laser particle size analyzer (LPSA, Horiba, Japan). Element compositions of the O-AS powders and C-AS particles were quantitatively analysed by using wavelength dispersive X-ray spectroscopy (WDS) in an electron probe X-ray microanalyzer (EPMA, EMAX-1770, Horiba, Japan) with the resolution of $110 \mathrm{ppm}$, operating voltage at $20 \mathrm{kV}$. In order to determine the element compositions of the original O-AS powders and C-AS particles accurately, five measurement points were randomly obtained in one image during analysis. The final value was calculated using 15 images selected randomly. The phase transformation of O-AS powders was characterized by X-ray diffraction (XRD, Philips X'Pert Pro, Holland) under room temperature with $\mathrm{Cu} K \alpha$ radiation of wavelength $1.5418 \AA$ A. The scanning $2 \theta$ angle ranged from $10^{\circ}$ to $90^{\circ}$ with a step scanning rate of $0.02 \% \mathrm{~min}$, 
while the voltage and electric current were held at $40 \mathrm{kV}$ and $30 \mathrm{~mA}$, respectively. The samples were determined three times, respectively. The obtained XRD patterns were analyzed by Jade software version 6.0 (Material's Data Inc., America).

Table 1 Spray parameters of YSZ by SAPS

\begin{tabular}{ccccccc}
\hline Current & Voltage & $\begin{array}{c}\text { Primary } \\
\text { gas }\end{array}$ & $\begin{array}{c}\text { Assistant } \\
\text { gas }\end{array}$ & $\begin{array}{c}\text { Carrier } \\
\text { gas }\end{array}$ & $\begin{array}{c}\text { Feeding } \\
\text { rate }\end{array}$ & $\begin{array}{c}\text { Spray } \\
\text { distance }\end{array}$ \\
\hline$(\mathrm{A})$ & $(\mathrm{V})$ & $(\mathrm{slpm})$ & $(\mathrm{slpm})$ & $(\mathrm{slpm})$ & $(\mathrm{g} / \mathrm{min})$ & $(\mathrm{mm})$ \\
430 & 150 & 120 & 24.2 & 7 & 35 & 100 \\
\hline
\end{tabular}

slpm: stard liter per minute

\section{Results and discussion}

\subsection{Characterization of the O-AS powders and C-AS particles}

Characteristics of the O-AS powders are shown in Fig. 3. The overall surface morphology of the O-AS powders and the high magnification SEM micrograph of a single powder are shown in Fig. 3 (a) and Fig. 3 (b), respectively. It can be seen that the O-AS powders are composed of agglomerated primary granules with 1-2 $\mu \mathrm{m}$ diameter. The O-AS powders with rough surface are near spherical morphology which can ensure good flow ability. Fig. 3 (c) and Fig. 3 (d) reveal the cross-sectional morphology of the O-AS powders, which indicates that the inside of particles has a relatively loose and porous microstructure. Fig. 4 and Fig. 5 show the surface and cross-sectional SEM micrographs of the C-AS particles passed through the SAPS plasma jet. Compared with the O-AS powders (Fig. 3), the C-AS particles after the SAPS plasma jet exhibit a smoother surface with high sphericity (Fig. 4 (a)) due to the 
surface of the O-AS powders was immediately melted by high temperature of the SAPS plasma jet when injected into the SAPS plasma jet and then surface of the melted particles became spherical under the effect of surface tension [20]. The surface texture of the C-AS particles can be clearly seen when the C-AS particles were more closely examined (see Fig. 4 (b)) which may be possibly due to the molten primary granules with 1-2 $\mu \mathrm{m}$ diameter were rapidly cooled and some roughly hexagonal shaped grains were formed. Fig. 4 (c) and Fig. 4 (d) display cross-sectional morphology of the C-AS particles, which indicate that the C-AS particles with a hollow structure are denser than the O-AS powders with a relatively loose and porous microstructure. This is because that the formation of a liquid outer layer prevented further escape of gas from the O-AS powders and the inner of the particles in-flight continued to melt with the increase of the flight distance [21]. As can be from Fig. 4, there are very smaller and exploded C-AS particles due to the trapped gas expanded when heated and the result of explosion and breakup was attributed to the effect of surface tension, shear force and pressure inside the particles in-flight. Besides, There are some big particles which may attribute to the collision and coalescence of the particles in-flight during the SAPS process (see Fig. 5(a)) [22]. Fig. 5 (b) shows the molten surface microstructure of the particles in-flight at the initial SAPS process stage.

\subsection{Particle size distribution of the O-AS powders and C-AS particles}

The particle size distribution of the O-AS powders and C-AS particles is given in Fig.5. The median particle sizes $\left(D_{50}\right)$ of the original AS YSZ particles and collected 
YSZ particles were $45.65 \mu \mathrm{m}$ and $42.04 \mu \mathrm{m}$, respectively. Values of $\mathrm{D}_{10}, \mathrm{D}_{50}$ and $\mathrm{D}_{90}$ were summarized in Table 2. As can be seen from the result, the particle size of the O-AS powders which were injected into the plasma jet obviously decreased during the SAPS process. The possible causes of particles in-flight refining were analysed as follows: 1) as the particles in-flight melt during the SAPS process, the particles in-flight become shrinking and denser; 2) The molten particles in-flight may breakup during the SAPS process that further results in the decrease of particle size. The smaller particle in-flight is able to form coatings with more complex maze structure which is beneficial for thermal insulation and anti-oxidation [23].

Table 2 Particle size distribution of the O-AS powders and C-AS particles

State of the YSZ particles

particle size $(\mu \mathrm{m})$

$\begin{array}{lccc} & \mathrm{D}_{10} & \mathrm{D}_{50} & \mathrm{D}_{90} \\ \text { O-AS powders } & 32.22 & 45.65 & 63.86 \\ \text { C-AS particles } & 30.16 & 42.04 & 60.34\end{array}$

\subsection{Element composition changes of the O-AS powders}

Element compositions of the O-AS powders and C-AS particles measured by EPMA are shown in Fig. 7. It can be seen from Fig. 7 that the element compositions of the O-AS powders and C-AS particles were the same. However, the content of zirconium $(\mathrm{Zr}, \sim 65.17 \mathrm{wt} \%)$ and yttrium $(\mathrm{Y}, \sim 7.07 \mathrm{wt} \%)$ in the O-AS powders particles was higher than the C-AS particles (Zr, 63.58 wt \%; Y, 4.29 wt \%), while the content of oxygen element in the O-AS powders was lower. This was probably related to the partial evaporation of $\mathrm{ZrO}_{2}$ and $\mathrm{Y}_{2} \mathrm{O}_{3}$ from the original AS YSZ particles 
during the SAPS process. When the O-AS powders were injected into the plasma jet, in which the temperature was about $10^{4} \mathrm{~K}$ and much higher than the boiling point of $\mathrm{ZrO}_{2}(\sim 4300 \mathrm{~K})$ and $\mathrm{Y}_{2} \mathrm{O}_{3}(\sim 4300 \mathrm{~K})$, the evaporation of $\mathrm{ZrO}_{2}$ and $\mathrm{Y}_{2} \mathrm{O}_{3}$ occurred [24]. As a result, the content of $\mathrm{Zr}$ and $\mathrm{Y}$ element was decreased. Furthermore, the decrease of Y ( 2.78 wt \%) was higher than $\operatorname{Zr}(\sim 1.59 \mathrm{wt} \%)$, which was ascribed to a higher vapor pressure of $\mathrm{Y}_{2} \mathrm{O}_{3}$ than $\mathrm{ZrO}_{2}$ at the elevated temperature (see Fig. 8) leading to a faster loss of $\mathrm{Y}_{2} \mathrm{O}_{3}$ than $\mathrm{ZrO}_{2}$ during the SAPS process [25].

\subsection{Phase transformation of the O-AS powders}

Fig. 9 shows the XRD patterns of the O-AS powders and C-AS particles. According to XRD patterns shown in Fig. 9 (a), $\mathrm{Y}_{\mathrm{O} .15} \mathrm{Zr}_{0.85} \mathrm{O}_{1.93}$, monoclinic zirconia $\left(\mathrm{m}-\mathrm{ZrO}_{2}\right)$ and Cubic Zirconia $\left(\mathrm{c}-\mathrm{ZrO}_{2}\right)$ were the main phases of the O-AS powders. It can be seen from Fig. 9 (b) that the C-AS particles were mainly composed of $\mathrm{Y}_{\mathrm{O} .15} \mathrm{Zr}_{0.85} \mathrm{O}_{1.93}$ and $\mathrm{c}-\mathrm{ZrO}_{2}$ phase. The disappearance of $\mathrm{m}-\mathrm{ZrO}_{2}$ phase in the O-AS powders during the SAPS process was attributed to phase transformation. As the O-AS powders were passed through the high temperature plasma jet, $\mathrm{m}-\mathrm{ZrO}_{2}$ in the O-AS powders changed into $\mathrm{t}-\mathrm{ZrO}_{2}$ over $1443 \mathrm{~K}$, and then $\mathrm{t}-\mathrm{ZrO}_{2}$ transformed into c- $\mathrm{ZrO}_{2}$ above $2643 \mathrm{~K}$ [26]. The phase transformation of pure $\mathrm{ZrO}_{2}$ is reversible. However, with the addition of $\mathrm{Y}_{2} \mathrm{O}_{3}$ stabilizing oxides in the crystalline of $\mathrm{ZrO}_{2}$ combined with relatively high cooling rates, the amount of phase transformation crystalline $\mathrm{ZrO}_{2}$ can undergo is limited during the SAPS process. Pure $\mathrm{ZrO}_{2}$ experiences the following phase transformation:

$$
\mathrm{m}-\mathrm{ZrO}_{2} \underset{1223 \mathrm{~K}}{\stackrel{1443 \mathrm{~K}}{\rightleftarrows}} \mathrm{t}-\mathrm{ZrO}_{2} \stackrel{2643 \mathrm{~K}}{\rightleftarrows} \mathrm{c}-\mathrm{ZrO}_{2} \stackrel{2953 \mathrm{~K}}{\rightleftarrows} \text { liq- } \mathrm{ZrO}_{2}
$$


A schematic diagram representing the development of physicochemical properties of YSZ particles in-flight during supersonic atmospheric plasma spray is shown in Fig. 10. The physicochemical properties of YSZ particles in-flight before impinging onto substrate can significantly influence the microstructure and phase composition of the as-sprayed coatings. The relationship between physicochemical properties of particles in-flight and the properties of high efficiency supersonic atmospheric plasma-sprayed YSZ coatings are still needed to be investigated.

\section{Conclusion}

In this study, the YSZ particles in-flight were successfully collected by a shock chilling method using a collection apparatus containing liquid nitrogen and its physicochemical properties of the melting state, morphology, microstructure, particle size, chemical composition changes and phase transformation during the SAPS process have been systematically investigated and the following conclusions can be drawn.

(1) The O-AS powders injected into the SAPS plasma jet were quickly heated and melted from the outer layer companied with breakup and collision-coalescence. The outer layer of the C-AS particles containing roughly hexagonal shaped grains exhibited a surface texture with high sphericity and the inside was dense with hollow structure.

(2) The molten YSZ particles in-flight become shrinking and denser and may 
breakup during the SAPS process. As a result, there is a refining phenomenon of particles in-flight during the SAPS process. The median particle sizes decreased from $45.65 \mu \mathrm{m}$ to $42.04 \mu \mathrm{m}$.

(3) The element compositions of the O-AS powders and C-AS particles are the same. However, the content of $\mathrm{Zr}$ and $\mathrm{Y}(\mathrm{wt} \%)$ in the O-AS powders particles was higher than the C-AS particles. The content of $\mathrm{Zr}$ and $\mathrm{Y}$ (wt \%) was decreased with the evaporation of $\mathrm{ZrO}_{2}$ and $\mathrm{Y}_{2} \mathrm{O}_{3}$ during the SAPS process, respectively. Furthermore, the decrease of Y ( 2.78 wt \%) was higher than $\mathrm{Zr}(\sim 1.59 \mathrm{wt} \%)$.

(4) Phase transformations took place during the SAPS process. The O-AS powders were mainly composed of $\mathrm{Y}_{0.15} \mathrm{Zr}_{0.85} \mathrm{O}_{1.93}, \mathrm{~m}-\mathrm{ZrO}_{2}$, and $\mathrm{c}-\mathrm{ZrO}_{2}$ phases; the corresponding C-AS particles were mainly composed of $\mathrm{Y}_{0.15} \mathrm{Zr}_{0.85} \mathrm{O}_{1.93}$ and $c-\mathrm{ZrO}_{2}$ phases. The $\mathrm{m}-\mathrm{ZrO}_{2}$ phase vanished during the SAPS process.

\section{Acknowledgements}

The authors acknowledge financial support by NSFC (51675531, 51535011 and 51675158), NSF of Beijing (3172038) and The Tribology Science Fund of State Key Laboratory of Tribology (SKLTKF16A05).

\section{References}

[1] C. Wang, T. Wu, $\mathrm{TiO}_{2}$ nanoparticles with efficient photocatalytic activity towards gaseous benzene degradation, Ceram Int. 41 (2015) 2836-2839.

[2] A.G. Evans, D.R. Clarke, C.G. Levi, The influence of oxides on the performance of advanced gas turbines, J. Eur. Ceram. Soc. 28 (2008) 1405-1419.

[3] R. Kitazawa, M. Tanaka, Y. Kagawa, Y.F. Liu, Damage evolution of TBC system 
under in-phase thermo-mechanical tests, Mater Sci Eng B-Adv. 173 (2010) 130-134.

[4] D.R. Clarke, S.R. Phillpot, Thermal barrier coating materials, Materials Today, 8 (2005) 22-29.

[5] H. Dong, G.J. Yang, H.N. Cai, H. Ding, C.X. Li, C.J. Li, The influence of temperature gradient across YSZ on thermal cyclic lifetime of plasma-sprayed thermal barrier coatings, Ceram Int. 41 (2015) 11046-11056.

[6] N.P. Padture, M. Gell, E.H. Jordan, Thermal barrier coatings for gas-turbine engine applications, Science 296 (2002) 280-284.

[7] Vijay, Kumar, Balasubramanian, Kandasubramanian, Processing and design methodologies for advanced and novel thermal barrier coatings for engineering applications, Particuology 27 (2016) 1-28.

[8] P. Fauchais, M. Vardelle, S. Goutier, Latest Researches Advances of Plasma Spraying: From Splat to Coating Formation, J. Therm. Spary. Techn. (2016) 1-20.

[9] Y. Bai, L. Zhao, J.J. Tang, S.Q. Ma, C.H. Ding, J.F. Yang, L. Yu, Z.H. Han, Influence of original powders on the microstructure and properties of thermal barrier coatings deposited by supersonic atmospheric plasma spraying, part II: Properties, Ceram Int. 39 (2013) 4437-4448.

[10] A. Vardelle, M. Vardelle, P. Fauchais, Influence of velocity and surface temperature of alumina particles on the properties of plasma sprayed coatings, Plasma Chem Plasma P. 2 (1982) 255-291.

[11] K. Liu, J. Tang, Y. Bai, Q. Yang, Y. Wang, Y. Kang, L. Zhao, P. Zhang, Z. Han, Particle in-flight behavior and its influence on the microstructure and mechanical property of plasma sprayed $\mathrm{La}_{2} \mathrm{Ce}_{2} \mathrm{O}_{7}$ thermal barrier coatings, Materials Science \& Engineering A, 625 (2015) 177-185.

[12] Y. Bai, L. Zhao, Y.M. Qu, Q.Q. Fu, Y. Wang, K. Liu, J.J. Tang, B.Q. Li, Z.H. Han, 
Particle in-flight behavior and its influence on the microstructure and properties of supersonic-atmospheric-plasma-sprayed nanostructured thermal barrier coatings, Journal of Alloys \& Compounds, 644 (2015) 873-882.

[13] T.A. Choudhury, N. Hosseinzadeh, C.C. Berndt, Artificial Neural Network application for predicting in-flight particle characteristics of an atmospheric plasma spray process, Surf. Coat. Technol. , 205 (2011) 4886-4895.

[14] T.A. Choudhury, C.C. Berndt, Z. Man, Modular implementation of artificial neural network in predicting in-flight particle characteristics of an atmospheric plasma spray process, Engineering Applications of Artificial Intelligence, 45 (2015) 57-70.

[15] W. Pei, Z. Wei, G. Zhao, J. Du, Y. Bai, The analysis of melting and refining process for in-flight particles in supersonic plasma spraying, Computational Materials Science, 103 (2015) 8-19.

[16] C. Tekmen, Y. Tsunekawa, M. Yoshida, M. Okumiya, Microstructural Characterization of In-flight Particles in Plasma Spray Process, Plasma Processes \& Polymers, 6 (2009) S223-S226.

[17] X.C. Zhang, B.S. Xu, Y.X. Wu, F.Z. Xuan, S.T. Tu, Porosity, mechanical properties, residual stresses of supersonic plasma-sprayed Ni-based alloy coatings prepared at different powder feed rates, Applied Surface Science, 254 (2008) 3879-3889.

[18] Y. Bai, L. Zhao, K. Liu, J.J. Tang, Z.H. Han, Fine-lamellar structured thermal barrier coatings fabricated by high efficiency supersonic atmospheric plasma spraying, Vacuum 99 (2014) 119-123.

[19] J.H. Yan, J.J. Xu, Rafi-ud-din, Y. Wang, L.F. Liu, Preparation of agglomerated powders for air plasma spraying MoSi 2 coating, Ceram Int. 41 (2015) 10547-10556. 
[20] R. Vassen, S. Schwartz, W. Jungen, Spray-drying of ceramics for plasma-spray coating, J. Eur. Ceram. Soc. 20 (2000) 2433-2439.

[21] G. Pravdic, M.S.J. Gani, The formation of hollow spherical ceramic oxide particles in a d.c. plasma, J. Mater. Sci. 31 (1996) 3487-3495.

[22] K.E.J. Lehtinen, M.R. Zachariah, Energy accumulation in nanoparticle collision and coalescence processes, J. Aerosol Sci. 33 (2002) 357-368.

[23] C. Wang, K. Li, X. Shi, C. Huo, Q. He, Y. Zhang, Effect of spraying power on oxidation resistance and mechanical properties of plasma sprayed La-Mo-Si coating, Surf. Coat. Technol. 311 (2017) 138-150.

[24] R.C. Garvie, Hannink, R.H. Amp, R.T. Pascoe, Ceramic steel, Nature 258 (1975) 703-704.

[25] L. Zhao, Y. Bai, J.J. Tang, K. Liu, C.H. Ding, J.F. Yang, Z.H. Han, Effect of particle in-flight behavior on the composition of thermal barrier coatings, Applied Surface Science 286 (12) (2013) 184-191.

[26] G.Y. Lin, T.C. Lei, Y. Zhou, In-situ TEM observations of tetragonal to monoclinic phase transformation in ZrO2-2 mol\% Y2O3 ceramics, Ceram Int. 24 (1998) 307-312 